\title{
Исследование структуры нитевидных нанокристаллов сульфида кадмия, синтезированных методом вакуумного испарения и конденсации в квазизамкнутом объеме
}

\author{
(C) А.П. Беляев ${ }^{1}$, В.В. Антипов ${ }^{2}$, В.П. Рубец ${ }^{2}$ \\ ${ }^{1}$ Санкт-Петербургская федеральная государственная химико-фрармацевтическая академия, \\ 197376 Санкт-Петербург, Россия \\ ${ }^{2}$ Санкт-Петербургский государственный технологический институт (технический университет), \\ 190013 Санкт-Петербург, Россия \\ E-mail: Alexei.Belyaev@pharminnotech.com
}

(Получена 14 апреля 2017 г. Принята к печати 24 апреля 2017 г.)

\begin{abstract}
Сообщается о результатах исследования кристалличности ансамбля нитевидных нанокристаллов сульфида кадмия с диаметром от 10 нм до единиц мкм и длиной в десятки мм, синтезированных из паровой фазы в квазизамкнутом объеме. Исследовались дифракция электронов и люминесценция. Приводятся дифракционные картины и микрофотографии. Результаты свидетельствуют о высокой степени кристалличности исследованных нитевидных нанокристаллов.
\end{abstract}

DOI: 10.21883/FTP.2018.01.45330.8604

Нитевидные нанокристаллы (ННК), впервые синтезированные в середине прошлого века, сегодня находят самое разнообразное применение. В медицине для тканевой инженерии [1-3] и для фотодинамической терапии [4], в электронике для создания высокоэффективных преобразователей солнечной энергии [5] и изготовления разного рода детекторов [6] и светодиодных структур [7], для элементов фотоники [8], в экологии для очистки сточных вод [9] и т.д.

Получают ННК, как правило, прецизионными методами, которые, несмотря на их сложность, не всегда обеспечивают высокое кристаллическое совершенство получаемых структур [10]. В работе[11] сообщалось о достаточно простом способе получения ННК - синтезе из паровой фазы в квазизамкнутом объеме, позволявшем получать нити диаметром от 10 нм до единиц мкм и длиной в десятки мм. Далее представлены результаты изучения кристаллического совершенства подобных систем.

В данной работе исследовался ансамбль ННК сульфида кадмия. Рост образцов осуществлялся в вакууме $\left(\sim 10^{-3}\right.$ Па), на установке ВУП-5, оборудованной специальной оснасткой по методике, подробно описанной в работе [12]. Микроскопические исследования проводились на просвечивающем электронном микроскопе ПЭМ-10.

Формирование ансамбля ННК осуществлялось из пара в специальном реакторе при ступенчатом варьировании температуры, обеспечивающем рост ННК в полном соответствии с модельными представлениями классического механизма пар - жидкость-кристалл Гиваргизова-Чернова [13]. Процесс начинался с образования ансамбля металлических капель кадмия, молекулы которого в силу их физических особенностей конденсировались из пара первыми. Затем в каплю попадали молекулы пара серы, где они вступали в реакцию с кадмием и образовывали пересыщенный жидкий раствор. Из раствора выпадали кристаллы сульфида кадмия, и под каплей формировались ННК.
Типичная микрофотография ансамбля ННК представлена на рис. 1.

Для исследования кристалличности ННК фрагменты ансамбля на специальной металлической сеточке (рис. 2) помещались под электронный пучок в мик-

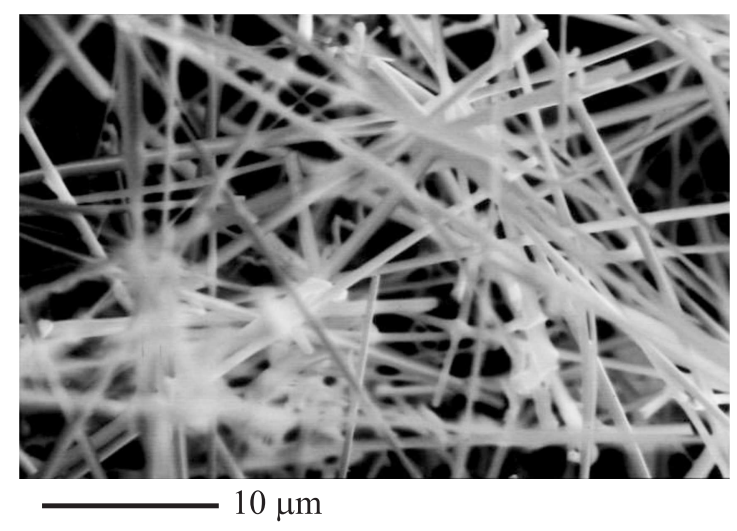

Рис. 1. Изображение ННК в электронном микроскопе.

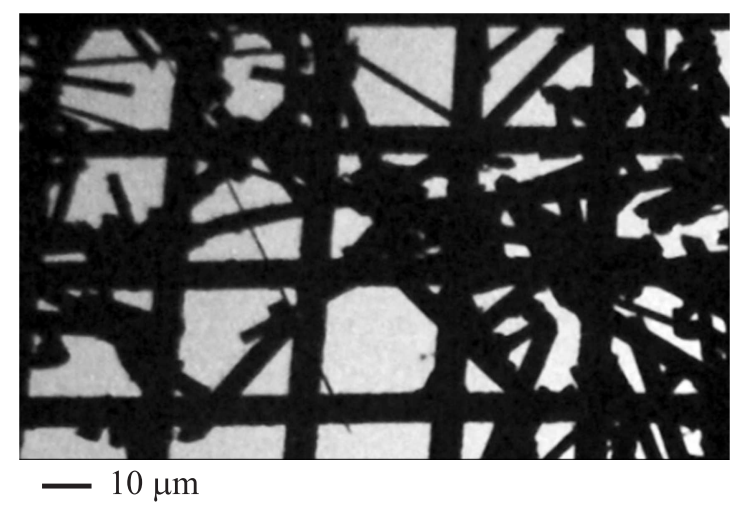

Рис. 2. Изображение фрагмента ансамбля ННК на металлической сеточке. 


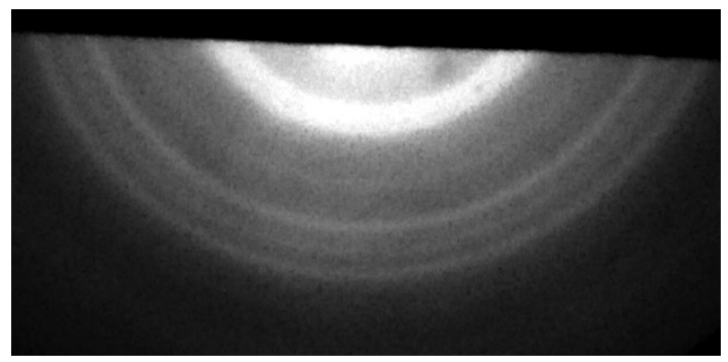

Рис. 3. Картина дифракции электронов от металлической сеточки.

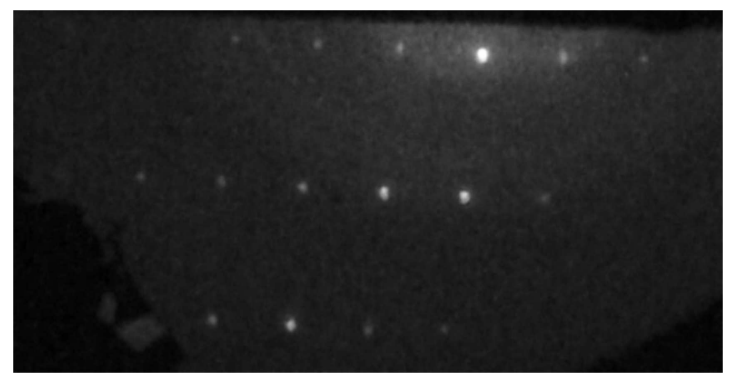

Рис. 4. Дифракционная картина фрагмента ансамбля ННК, расположенного на металлической сеточке.

роскопе. Однако полезный сигнал, получаемый под сфокусированным пучком оказывался крайне слабым, и луч приходилось расфокусировать. При этом возникала опасность попадания в полезный сигнал от ансамбля ННК дифракционной картины от материала сеточки.

Чтобы учесть возможное влияние сеточки, выполнялись измерения диффрации электронов отожженной сеточки, незаполненной элементами ННК (рис. 3). Она однозначно свидетельствует о поликристаллической структуре материала, из которого изготовлена сеточка.

На рис. 4 представлена дифракционная картина, полученная от фрагмента ансамбля ННК, расположенного на сеточке. Как можно видеть, картина носит характер, свойственный кристаллическим системам на слабом фоне размытых окружностей, связанных с отожженной сеточкой. Полученный результат позволяет предположить, что дифракционная картина (см. рис. 4). представляет собой суперпозицию двух дифракционных картин: от поликристаллической сеточки и от кристаллического ансамбля ННК.

Кристалличность ансамбля ННК, синтезированного методом квазизамкнутого объема из паровой фазы, подтверждается его люминесцентными свойствами. При облучении ансамбля при комнатной температуре светом с длиной волны 395 нм наблюдалось голубое свечение.

На основании представленных результатов можно констатировать, что нитевидные нанонокристаллы сульфида кадмия с диаметром от 10 нм до единиц мкм и длиной в десятки мм, синтезированные из паровой фазы в квазизамкнутом объеме, обладают высокой степенью кристалличности.

\section{Список литературы}

[1] Q. Wang, S. Chen, D. Chen. J. Mech. Behav. Biomed. Mater., 65, 466 (2017).

[2] G.K. Tummala, T. Joffre, V.R. Lopes, A. Liszka, O. Buznyk, N. Ferraz, M. Griffith, A. Mihranyan. ACS Biomater. Sci. Eng., 2, 2072 (2016).

[3] E.H. Fragal, T.S.P. Cellet, V.H. Fragal, M.V.P. Companhoni, T. Ueda-Nakamura, E.C. Muniz, R. Silva, A.F. Rubira. Carbohyd. Polymers, 152, 734 (2016).

[4] F.U. Rehman, C. Zhao, H. Jiang, M. Selke, X. Wang. J. Nanosci. Nanotechnol., 16, 12691 (2016).

[5] Q. Zhang, J. Lang, J. Su, X. Li, H. Zhai, J. Wang, J. Yang. Chem. Phys., 469-470, 79 (2016).

[6] A. Renitta, K. Vijayalakshmi. Sens. Actuators B, 237, 912 (2016).

[7] В.В. Лундин, С.Н. Родин, А.В. Сахаров, Е.Ю. Лундина, С.О. Усов, Ю.М. Задиранов, С.И. Трошков, А.Ф. Цацульников. ФТП, 51, 101 (2017).

[8] А.В. Павликов, Н.В. Латухина, В.И. Чепурнов, В.Ю. Тимошенко. ФТП, 51, 421 (2017).

[9] S. Kumari, G.S. Chauhan, J.-H. Ahn. Chem. Eng. J., 304, 728 (2016).

[10] В.В. Симаков, И.В. Синёв, А.В. Смирнов, А.И. Гребенников. ЖТФ, 86, 96 (2016).

[11] А.П. Беляев, В.П. Рубец, В.В. Антипов. ФТП, 50, 420 (2016).

[12] А.П. Беляев, В.П. Рубец, В.В. Антипов. ЖФХ, 91, 345 (2017).

[13] Е.И. Гиваргизов. Рост нитевидных и пластинчатых кристаллов из пара (М., Наука, 1977).

Редактор А.Н. Смирнов

\section{Study ot the structure of threadlike nanocrystals of cadmium sulfide synthesized by vacuum evaporation metod and condtnsation in quasi-closed volume}

A.P. Belyaev' ${ }^{1}$, V.V. Antipov², V.P. Rubets ${ }^{2}$

${ }^{1}$ St. Petersburg State

Chemical-Pharmaceutical Academy,

197376 St. Petersburg, Russia

${ }^{2}$ St. Petersburg State Institute of Technology

(Technical University),

190013 St. Petersburg, Russia

Abstract The results of the study of crystallinity of the ensemble of threadlike nanocrystals of cadmium sulfide of diameter from $10 \mathrm{~nm}$ up to several $\mu \mathrm{m}$ and length of tens mm, synthesized by vacuum evaporation in quasi-closed volume are reported. An electron diffraction and luminescence were studied. The result obtained testify about high degree of crystallinity of studied threadlike nanocrystals. 